\title{
BUANA PENDIDIKAN
}

http://jurnal.unipasby.ac.id/index.php/jurnal_buana_pendidikan/index

\section{Pengembangan Video Program Stimulus Visual Auditori Pada Anak Dislexia Bagi Guru}

\author{
Angga Eryana \\ Pascasarjana, Universitas Negeri Surabaya \\ Jl. Lidah Wetan, Surabaya, Jawa Timur, Indonesia \\ anggaeryana16070915006@mhs.unesa.com
}

Informasi Artikel
Kata kunci:
Visual, Auditori,
membaca, Disleksia

Diterima: 10-11-2020
Disetujui: 13-11-2020
Dipubikasikan: $15-11-2020$

\begin{abstract}
Abstrak
Tujuan penelitian ini adalah untuk meningkatkan keterampilan membaca yang khusus diterapkan pada siswa dengan kesulitan belajar. Penelitian ini untuk menguji kelayakan validitas Program Video Auditory Visual Stimulus pada Anak Disleksia Bagi Guru. Metode penelitian ini menggunakan pendekatan Reseach and Development ( $\&$ \& ) dengan pengembangan model 4D yaitu define, design, develop, dan disseminate. Penelitian ini hanya menggunakan 3 tahap pengembangan yaitu define, design dan devlop. Hasil yang diperoleh nilai validasi antara lain: (1). Nilai keseluruhan indikator validasi ahli media adalah 89,5\% dengan sangat layak, (2) Nilai keseluruhan indikator validasi ahli materi adalah $81,1 \%$ dengan sangat layak. Dengan demikian dapat disimpulkan bahwa hasil Program Video Auditory Visual Stimulus untuk Anak Disleksia Guru layak
\end{abstract} dan efektif untuk guru dalam mengajarkan membaca kepada anak disleksia.

\begin{tabular}{l}
\hline Abstact \\
The purpose of this study is to improve reading skills that are specifically applied \\
to students with learning difficulties. This study is to test the feasibility of the \\
validity of the Video Auditory Visual Stimulus Program in Dyslexic Children for \\
Teachers. This research method uses the Reseach and Development (R \& D) \\
approach with the development of the 4D model that is define, design, develop, \\
and disseminate. This study only uses 3 stages of the development of define, \\
design and devlop. The results obtained by validation values include: (1). The \\
overall value of the media expert validation indicator is $89.5 \%$ with very feasible, \\
(2) The overall value of the material expert validation indicator is $81.1 \%$ with \\
very feasible. It can be concluded that the results of the Video Auditory Visual \\
Stimulus Program for Dyslexic Children for Teachers are feasible and effective \\
for teachers to teach reading to dyslexic children.
\end{tabular}

Keywords:

Visual, Auditory, Reading, Dyslexia 


\section{PENDAHULUAN}

Peserta didik kesulitan belajar (disleksia) memiliki karakteristik lemah dalam kesadaran linguistik dan persepsi visual. Padahal keduanya memiliki peranan yan sangat penting dalam pembelajaran membaca. Sehingga kedua hal ini tidak dapat dipisahkan terutama bagi peserta didik disleksia dalam belajar membaca. Namun metode yang bekembang tidak sebanding, oleh karena itu dianggap perlu mengangkat tentang kesadaran ingustik agar pembelajaran membaca yang berkembang dapat seimbang bagi peserta didik disleksia.

(Kawuryan and Raharjo, 2012) mendefinisikan bahwa disleksia adalah suatu kondisi yang ada kaitannya dengan kemampuan membaca yang sangat buruk. Buruknya kemampuan membaca seseorang yang mengalami disleksia tidak berkaitan dengan IQ yang dimilikinya. Individu yang mengalami disleksia memiliki IQ normal bahkan diatas rata-rata. (Olua, 2019) menjelaskan disleksia dengan terperinci. Individu yang mengalami disleksia akan kesulitan mengeja, membaca, menulis dan akan mengalami kesulitan dalam menafsirkan atau mengartikan struktur kata yang memberikan pengaruh saat proses belajar. Karakteristik peserta didik dengan kesulitan belajar (disleksia) memiliki kesulitan dalam pengolahan fonologi. Hal ini masuk kedalam ranah kesadaran linguistic .

Anak dengan disleksia memiliki masalah dalam kesadaran vonem. Mereka tidak seperti anak pada umumnya yang mampu dengan sendiri untuk memahami penggabungan huruf. Mengeja seperti "b-a" maka di baca "ba" sulit dicerna oleh mereka, hal ini disebabkan yang diajarkan kepada mereka lambang huruf dan yang diminta untuk dibaca adalah bunyi huruf. Perlu adanya teknik khusus untuk memberikan anak disleksia kesadaran vonem agar kesadaran bunyi huruf dapat dibangkitkan. Menurut Akhadiah dalam (Rahman and Haryanto, 2014) mengunkapkan pengertian tentang membaca permulaan diberikan pada siswa kelas I dan kelas II. Ia juga mengutarakan siswa dituntut untuk mengnali bunyi, melafalkan huruf - huruf, suku kata, kata - kata kedalam bentuk lisan yang tepat (Jauhari, M. N. 2016).

Lloyd mengungkapkan tentang metode Jolly Phonics sebagai alternative pengenalan huruf (Dwiastuti, 2018). Seefeldt dan Wasik menjelaskan tahapan pengajaran bunyi dalam Jolly Phonics yang pertama adalah sintesa bunyi (identifikasi bunyi) dengan cara menunjukan bunyi dari setiap huruf baru kemudian menggabungkan bunyi-bunyi tersebut menjadi bunyi kata (Dwiastuti, 2018). Metode ini diperkuat oleh Jhonston dkk bahwa pembelajaran membaca fonemik sangat evektif bagi anak-anak (Dwiastuti, 2018). Stuart juga meneliti tentnag pembelajaran membaca dengan menggunakan metode fonemik yang hasilnya pendekatan fonemik membuat anak lebih cepat menguasai kemampuan membaca dan menulis (Dwiastuti, 2018). Stimulus visual-auditori adalah program yang disusun oleh peneliti sebelumnya yang hendak di kembangkan dalam bentuk video tutorial. program ini dinilai dapat membenjadi rumusan yang tepat untuk meningkatkan kemampuan membaca pada anak disleksia. Namun program ini belum tertuang dalam bentuk video tutorial. Diharapkan video tutorial dapat menjadi media komunikasi yang cukup jelas untuk membrikan gambaran proses detail penerapan program tersebut. 
Salah satu urgent dalam penelitian ini adalah kemampuan membaca yang harus dimiliki siswa guna mempelajari dan memahami pengetahuan yang sifatnya tekstual. Dengan stimualsi visual auditoris ini anak juga akan mengoreksi bunyi bicara yang keluasr apakah sesuai dengan apa yang mereka lihat (visual) betupa gerak bbit dan pola pengucapan yang benar dan juga apakah bunyi bicara yang dihasilkan sudah sama atau sesuai dengan apa yang mereka dengar.

Peran orang tua sangat diperlukan dalam pemantapan materi yang sudah diberikan di sekolah. Bagaimana mengucapkan bunyi dari setiap kata, bagaimana menyampaikan kepada anak agar lebih tepat hal ini perlu dikuasai oleh orang tua. Namun akan sangat sulit menyampaikan teknik-tekniknya secara detail agar tidak terjadi kesalahan. Oleh karena itu peneliti tertarik ingin membuat video program stimulus visualauditori pada anak disleksia bagi orang tua dan guru untuk meningkatkan kemampuan membaca yang khusus diterapkan bagi peserta didik - peserta didik tersebut. pengembangan video program stimulus VisualAuditori pada anak disleksia bagi orang tua dan guru ini adalah aplikasi dari teori-teori pengajaran membaca bagi kesulitan belajar (disleksia) dan teori kebahasaan (bahasa indonesia). Video program stimulus visualauditori pada anak disleksia bagi orang tua dan guru yang nantinya akan mudah diaplikasikan bagi guru non PLB, guru PLB yang konsentrasinya bukan kesulitan belajar, dan orang tua. Buku ini juga dapat digunakan di Sekolah Luar Biasa dan inklusi yang didalamnya terdapat peserta didik siswi dengan kehususankekhususan diatas.

\section{METODE}

Penelitian ini menggunakan pendekatan kualitatif dengan jenin penelitian pengembangan Research and Development ( $\mathrm{R} \& \mathrm{D})$. penelitian ini akan menghasilkan produk berupa pengembangan video program stimulus visual auditori untuk siswa dengan kesulitan belajar. Penelitian yang dilakukan hanya sampai pada kelayakan saja dikarenakan terjadi wabah covid -19 yang tidak memungkinkan untuk dilakukan penelitian kelapangan untuk menguji keefektifan produk. Tahap perancanagan bertujuan menghasilkan rancangan panduan parenting untukn anak rtardasi mental pada masa pubertas. Hasil dari perancangan ini disebut draf I. Berikut kegiatan yang ada pada tahap ini : 1. Pemilihan media, 2. Pemilihan format, 3. Perancanagn awal, Tahap Develop, Dalam tahap develop bertujuan untuk mengahasilkan draf final yaitu Pengembangan Video Program Stimulus Visual Auditori Pada Anak Dislexia Bagi Guru. Video program stimulus visual auditori pada anak dislexia bagi guru, menggunakan analisis data kevalidan skala linkert hasil dan validasi menggunakan perhitungan rata-rata mean sederhana.

Tabel 1. Kriteria Kevalidan Video Program Stimulus Visual Auditori Pada Anak Dislexia Bagi Guru

\begin{tabular}{ccc} 
Tingkat & Kualifikasi & Ketreangan \\
\hline $85 \%-100 \%$ & Sangat Layak & Sangat Layak \\
\hline $75 \%-84 \%$ & Layak & Layak \\
\hline $65 \%-74 \%$ & Cukup Layak & Kurang Layak \\
\hline $64 \%-55 \%$ & Kurang Layak & Tidak Layak \\
\hline $0 \%-54 \%$ & Tidak Layak & \\
\hline
\end{tabular}




\section{HASIL DAN PEMBAHASAN}

Pada bab ini akan memaparkan hasil pengembangan video program Stimulus Visaul Autditori pada anak dislexia bagi guru dan pembahasan kelayakan dari segi kevalidan produk pengembangan.

\section{Tahap Pendefinisian (Diffine)}

Kebutuhan anak dislexia disekolah inklusi, yang dimana guru pada umumnya kesulitan dalam memberikan layanan pembelajaran yang tepat. Terdapat anak yang memang pada tingkatan kelas 5 dan 6 belum memiliki kemampuan membca yang baik. hal ini terjadi di SDN Pegangsaan 02 jakarta utara. Hal ini sesuai dengan yang di utarakan oleh Raharjo mengungkapkan hasil indentifikasi yang ia lakukan bahwa anak masih mengalami ketidak mampuan membaca pada tingkat kelas 4 dan 5 (Kawuryan and Raharjo, 2012). Hal ini terjadi karena memang disekolah tersebut tidak terdapat guru pembimbing khusus, namun guru cukup mengenali jika ada anak yang memerlukan perhatian khusus karena di kelas 5 belum dapat membaca. Hal selaras juga diungkapkan oleh Rowan yang berpendapat bahwa dyslexia memiliki kemampuan membaca dibawah rata-rata walaupun kemampuan IQ-nya tinggi atau normal (Irdamurni et al., 2018).

Analisis akhir didasarkan pada temuan dilapangan melalui observasi di lapangan yang pada akhirnya memerlukan adanya pengembangan suatu program untuk mengatasi masalah. Adanya permasalahan program pembelajaran membaca kurang evisien bagi siswa kesulitan belajar (dislexsia). Dalam penelitian ini yang menjadi permasalahan dasar melalui hasil observasi di lapangan, adalah Program pembelajaran membaca kurang evisien bagi siswa kesulitan belajar (dislexsia) sebagai salah satu bentuk layanan yang ada di sekolah. Dalam memberikan layanan, diperlukan pengetahuan dari guru di sekolah inklusi tentang cara pelaksanaan layanan membaca. Kemudian dicarikan jalan keluar berupa pengembangan video program stimulus visual auditori untuk siswa dengan kesulitan belajar.

Daryanto dalam (Hadi, 2017) mengemukakan bahwasanya video juga termasuk kedalam media audio visual. Ia menyatakan bahawa dalam media video indra yang digunakan adalah indra penglihatan dan indra pendengaran sehingga video sangat efektif digunakan sebagai perantara pembelajaran secara masalah ataupun individual. Gerlach dan Ely dalam (Lutfi et al., 2013) mengungkapkan media visual auditori dapat digunakan dalam pembelajaran lingkup individual dan lingkup pembelajaran clasikal. Media visual auditori adalah media yang melibatkan indra pendengaran dan indra penglihatan secara bersamaan (Lutfi et al., 2013). Cheppy Riyana (2007:2 ) mengemukakan video pembelajaran adalah penyajian audio visual yang didalmnya terdapat pesan - pesan baik berupa konsep, prinsip, aturan, tahapan dalam pelaksanaan suatu teori. Video merupakan gambar bergerak seperti didalam bentuk videotape, videodisc, DVD, dan computer disc.

\section{Tahap Design}

Produk Pengembangan Video Program Stimulus Visual Auditori Pada Anak Dislexia Bagi Guru. Tertuang dalam bentuk DVD dan bahan penyerta berupa buku. Video disajikan dalam bentuk DVD yang dapat dioperasikan di computer PC, laptop (CD room) dan DVD player. DVD berukuran $120 \mathrm{~mm}$ (4,7 in) dan dapat menyimpan hingga 45 menit audio terkompresi atau 5,00 GB (5,000 byte) data. 
Cover CD Pengembangan Video Program Stimulus Visual Auditori Pada Anak Dislexia Bagi Guru. CD diberi cover untuk melindungi $\mathrm{CD}$ tersebut. Cover $\mathrm{CD}$ berwarna dasar ungu, dengan corak kuning sebagai tambahan. Bahan cover CD terbuat dari bahan plastik. Pada posisi pojok kiri atas terdapat logo UNESA dan tertulis jurusan Pendidikan Khusus, Fakultas Ilmu Pendidikan, Universitas Negeri Surabaya, serta jenjang Pasca Sarjana dengan font Arial Black dengan ukuran 13. Pada bagian tengah cover tertulis judul penelitian dengan font comic sans ms ukuran font 25. Bagian bawah judul tertulis penjelasan singkat tentang isi materi dalam video. Pada bagian bawah materi tertulis nama peneliti dengan font Arial ukuran 20.

\section{Tahap Develop}

Pada tahap pengembangan diawalai dengan pembuatan naska, storyboard, dan untuk proses pembuatan video itu sendiri peneliti meminta bantuan tenaga ahli. Hal ini selaras dengan (Riyana, 2007) terkait tahapan pengembangan video adalah tahapan identifikasi kebutuhan dan karakteristik siswa, perumusan tujuan, materi, pengembangan alat pengukur keberhasilan, naskah media, dan merumuskan instrument dan instrument revisi. Adapun spesifikasi fisik da nisi yang dibuat adalah dalam bentuk video agar mudah diulang dan ditiru oleh guru. Terdapat juga bahan penyerta guna mempermudah guru dalam memahami isi video.

Hal ini selaras dengan Brunner dalam (Hadi, 2017) mengemukakan efektivitas penggunaan video sebagai perantara menyampaikan pesan. Penelitian lain juga menyatakan Heinich dan Arsyad menyatakan dalam (Hadi, 2017) bahwa video memiliki manfaat yaitu perantara terhadap sesuatu. Semntara dalam kontek pembelajaran media video berperan sebagai perantara tersampaikannya materi dari guru kepada siswa.

\section{Uji Kevalidan}

Dari hasil rumusan masalah yang dipaparkan terjawablah masalah seperti kurangnya metode membaca yang diketahui guru, kebingungan guru akan teknik pembelajaran membaca, ketidak tahuan guru media apa saja yang digunakan dan belum adanya video yang mengajarkan teknis pelaksanan membaca untuk anak dislexia. Hasil analisis data dari para ahli tentang kevalidan produk pengembangan video stimulus visual auditori pada anak dislexia bagi guru setelah revisi dinyatakan kelayakannya oleh para ahli.

Dari segi materi sebagaimana diungkapkan Thiagarajan (1974) mengungkapkan sudah seharunya prototype media pembelajaran a divalidasi oleh ahli materi dan mengkaji aspek sajian materi dan aspek pembelajaran. Dalam video Video Program Stimulus Visua Auditori Pada Anak Disleksia terdapat poinpoin yang menjadi penilaian ahli materi, yaitu penjelasan dalam opening video. Penjelasan dalam opening video mendapat penilan sangat baik yang arinya cukup menjelaskan tujuan dari pembelajaran yang ada didalam video.

Isi materi video terdapat langkah-langkah pelaksanaan program pembelajaran memebaca. Langkahlangkah tersebut berupa gambar audio visual dan tulisan yang terletak dipojok kanan atas sebagai tambahan penjelasan. Pada bagian ini juga mendapat penilaian sangat baik. 
Pada bagian evaluasi mendapat hasil penilaian yang beragam, namun jika dirata-ratakan masuk pada kriteria baik. Jadi dapat disimpulkan secara keseluruhan hasil analisi validasi ahli materi terhadap Video Program Stimulus Visua Auditori Pada Anak Disleksia dilihat dari perhitungan diatas, diperoleh persentase sebesesar 89,5\% memiliki kwalitas yang "sangat layak" untuk digunakan.

Kesimpulan sangat layak yang didapat dari segi isi materi menjadi landasan peneliti bahwa dengan melihat video ini guru dapat memahami metode pembelajaran membaca untuk anak dislexia, langkahlangkah yang dimaksud dalam video ini. Serta memudahkan guru dalam menentukan media belajar yang tepat untuk pembelajaran. Setelah produk pengembangan selesai disusun, maka langkah selanjunta adalah meminta penilaian atau validasi ahli media bidang keilmuan pendidikan luar biasa. Adapun aspek yang dinilan dari ahli media adalah tentang bagian fisik DVD, bagian opening, bagian sambutan dan langkah-langkah pembelajaran, bagian kegiatan pembelajaran, dan evaluasi pembelajaran, dan bahan penyerta yang berupa buku.

Pada bagian fisik DVD mendapatkan rata-rata penilaian baik. Sementara pada aspek opening melihak kemenarikan, kesesuaian, ketepatan, dan durasi dari vidio ini mendapatkan penilaian cukup baik. Bagian sambutan dan langkah-langkah untuk durasi, dan kesesuaian video mendapatkan penilaian sangat baik. Sementara untuk kegiatan pembelajaran mendapatkan penilaian rata-rata baik. Untuk bagian evaluasi pelaksanaan dalam video mendapatkan nilai yang sangat baik. Pada bagian bahan penyerta validator memberikan nilai baik. Sehingga hasil analisis validasi media terhadap Video Program Stimulus Visua Auditori Pada Anak Disleksia dari perhitungan data di atas, diperoleh persentase sebesar 81,1\%. Hasil perhitungan tersebut dapat menunjukkan tingkat kelayakan produk Video Program Stimulus Visua Auditori Pada Anak Disleksia. Sehingga dapat disimpulkan bahwa berdasarkan tabel diatas, media Video Program Stimulus Visua Auditori Pada Anak Disleksia memiliki kelayakan yang “Sangat layak” untuk digunakan. Hasil secara keseluruhan dari segi penyajian dalam bentuk video sangat layak digunakan sehingga diharapkan dengan tampilan video dapat memunculkan ketertarikan dalam pembelajaran. Serta pemahaman guru setelah melihat video mampu memberikan pembelajaran membaca yang optimal.

\section{KESIMPULAN}

Berdasarkan hasil pengembangan produk media Video Program Stimulus Visua Auditori Pada Anak Disleksia yang sudah dilakukan, maka dapat diambil kesimpulan kelayakan hasil analisi validasi ahli materi terhadap Video Program Stimulus Visual Auditori Pada Anak Disleksia dilihat dari perhitungan diatas, diperoleh persentase sebesesar 89,5\%. Sehingga dapat disimpulkan bahwa berdasarkan tabel diatas Video Program Stimulus Visua Auditori Pada Anak Disleksia memiliki kwalitas yang "sangat layak" untuk digunakan. Sementara analisis validasi media dan bahan penyerta terhadap Video Program Stimulus Visua Auditori Pada Anak Disleksia dari perhitungan data di atas, diperoleh persentase sebesar 81,1\%. Sehingga dapat disimpulkan bahwa berdasarkan tabel diatas, media Video Program Stimulus Visua Auditori Pada Anak. Disleksia memiliki kelayakan yang “Sangat layak” untuk digunakan. Dari semua perolehan diatas sehingga semua pengembangan produk yang dibuat sangat layak untuk digunakan 


\section{DAFTAR PUSTAKA}

Ali, M., 2009. Pengembangan Media Pembelajaran Interaktif Mata Kuliah Medan Elektromagnetik 5, 8.

Anwar, A.R.K., 2014. Efektifitas Metode Gillingham Untuk Meningkatkan Kemampuan Membaca Permulaan Siswa Kesulitan Belajar Kelas Iii Sd N 01 Limau Manis Padang 3, 12.

Dwiastuti, I., 2018. Metode Jolly Phonics Sebagai Alternatif Stimulasi Kesiapan Membaca Anak Usia Dini. J. Sains Psikol. 3.

Faturahman, H., 2015. Peningkatan Kemampuan Pemecahan Masalah Matematika Siswa Dengan Penerapan Pendekatan Visual - Auditori - Kinestetik (Vak). Fibonacci J. Pendidik. Mat. Dan Mat. 1, 57-63. Https://Doi.Org/10.24853/Fbc.1.1.57-63

Gesti, E.K., Ardoni, A., 2018. Pembuatan Video Panduan Layanan Perpustakaan Di Perpustakaan Universitas Andalas. Ilmu Inf. Perpust. Dan Kearsipan 7, 40-46-46. Https://Doi.Org/10.24036/100915-0934

Ghofur, M.A., 2016. Pelaksanaan Quantum Teaching Untuk Meningkatkan Kompetensi Pedagogik Guru Sekolah Dasar. Pedagog. J. Pendidik. 5, 255-266-266. Https://Doi.Org/10.21070/Pedagogia.V5i2.258

Hadi, S., 2017. Efektivitas Penggunaan Video Sebagai Media Pembelajaran Untuk Siswa Sekolah Dasar. Semin. Nas. Teknol. Pembelajaran Dan Pendidik. Dasar 2017 0, 96-102.

Herlinda, F., 2014. Meningkatkan Kemampuan Membaca Kata Melalui Media Audio Visual Bagi Anak Slow Learner. J. Penelit. Pendidik. Khusus 3. Https://Doi.Org/10.24036/Jupe35000.64

Idzhar, A., 2016. Peranan Guru Dalam Meningkatkan Motivasi Belajar Siswa. J. Off. 2, 221-228. Https://Doi.Org/10.26858/Jo.V2i2.2956

Indriati, E., 2015. Kesulitan Bicara Dan Berbahasa Pada Anak. Prenada Media.

Irdamurni, I., Kasiyati, K., Zulmiyetri, Z., Taufan, J., 2018. Meningkatkan Kemampuan Guru Pada Pembelajaran Membaca Anak Disleksia. J. Pendidik. Kebutuhan Khusus 2, 29-32.

Jauhari, M. N. (2016). Identifikasi Perkembangan Komunikasi Anak Pervasive Developmental Disorder. HELPER: Jumal Bimbingan dan Konseling, 32(2).

Kawuryan, F., Raharjo, T., 2012. Pengaruh Stimulasi Visual Untuk Meningkatkan Kemampuan Membaca Pada Anak Disleksia. J. Psikol. Pitutur 1, 9-18.

Knoop-Van Campen, C.A.N., Segers, E., Verhoeven, L., 2020. Effects Of Audio Support On Multimedia Learning Processes And Outcomes In Students With Dyslexia. Comput. Educ. 150, 103858. Https://Doi.Org/10.1016/J.Compedu.2020.103858

Lestari, W., Zulmiyetri, Z., 2019. Meningkatkan Kemampuan Membaca Kata Melalui Media Video Pembelajaran Bagi Anak Tunarungu. J. Penelit. Pendidik. Khusus 7, 71-76-76.

Lutfi, M., Sudirman, Pramitha, R., 2013. Sisi-Sisi Lain Kebijakan Profesionalisme Guru: Optik Hukum, Implementasi, Dan Rekonsepsi. Universitas Brawijaya Press.

Meyer, O.A., Omdahl, M.K., Makransky, G., 2019. Investigating The Effect Of Pre-Training When Learning Through Immersive Virtual Reality And Video: A Media And Methods Experiment. Comput. Educ. 140, 103603. Https://Doi.Org/10.1016/J.Compedu.2019.103603 
Mulyani, D., 2019. Peningkatan Kemampuan Pengucapan Konsonan Bilabial [B] Dan [P] Melalui Metode Visual Auditori Kinestetik Dan Taktil Bagi Siswa Tunarungu Kelas Dasar 5a Di Slb B Karnnamanohara. Widia Ortodidaktika 8, 157-166.

Olua, E., 2019. Peningkatan Kemampuan Membaca Permulaan Melalui Permainan Huruf Dan Kata Dengan Gaya Belajar Visual, Auditori Dan Kinestetik. J. Inov. Ilmu Pendidik. 1, 1-14.

Pengembangan Media Komik Untuk Meningkatkan Motivasi Belajar Dan Keterampilan Membaca Pemahaman Siswa Kelas Iv | Budiarti | Jurnal Prima Edukasia [Www Document], N.D. Url Https://Journal.Uny.Ac.Id/Index.Php/Jpe/Article/View/6295/Pdf (Accessed 6.19.20).

Purwanti, B., 2015. Pengembangan Media Video Pembelajaran Matematika Dengan Model Assure. J. Kebijak. Dan Pengemb. Pendidik. 3. Https://Doi.Org/10.22219/Jkpp.V3i1.2194

Rahman, B., Haryanto, H., 2014. Peningkatan Keterampilan Membaca Permulaan Melalui Media Flashcard Pada Siswa Kelas I Sdn Bajayau Tengah 2. J. Prima Edukasia 2, 127-137. Https://Doi.Org/10.21831/Jpe.V2i2.2650

Riyana, Cepi, 2007. Media Pembelajaran: Hakikat,Pengembangan,Pemanfaatan,Dan Penilaian - Drs.Rudi Susilana, M.Si. \& Cepi Riyana, M.Pd. - Google Books [Www Document]. Url Https:/ Books.Google.Co.Id/Books?Hl=En\&Lr=\&Id=Yqhawaaqbaj\&Oi=Fnd\&Pg=Pr3\&Dq $=$ Buku ++ Media + Pembelajaran + Suatu + Pendekatan + Baru\&Ots=Ejwkzulo5\&Sig $=$ Gdfbyo3zq nw0dx0diwdxb2j27xo\&Redir_Esc=Y\#V=Onepage\&Q\&F=False (Accessed 6.18.20).

Soriano-Ferrer, M., Morte-Soriano, M., 2017. Teacher Perceptions Of Reading Motivation In Children With Developmental Dyslexia And Average Readers. Procedia - Soc. Behav. Sci. 237, 50-56. Https://Doi.Org/10.1016/J.Sbspro.2017.02.012

Supriyono, K., Sugirin, S., 2014. Pengembangan Media Pembelajaran Membaca Bahasa Inggris Smp Berbasis Web. J. Inov. Teknol. Pendidik. 1, 49-64. Https://Doi.Org/10.21831/Tp.V1i1.2459

Video Editing \& Video Production Book By Wahana Komputer - Gramedia Digital [Www Document], N.D. Url Https://Ebooks.Gramedia.Com/Books/Video-Editing-Video-Production (Accessed 6.18.20).

Wang, X., Lin, L., Han, M., Spector, J.M., 2020. Impacts Of Cues On Learning: Using Eye-Tracking Technologies To Examine The Functions And Designs Of Added Cues In Short Instructional Videos. Comput. Hum. Behav. 107, 106279. Https://Doi.Org/10.1016/J.Chb.2020.106279 